\begin{tabular}{|c|c|c|c|c|c|c|}
\hline \multirow{4}{*}{ Impact Factor: } & ISRA (India) & $=3.117$ & SIS (USA) & $=0.912$ & ICV (Poland) & $=6.630$ \\
\hline & ISI (Dubai, UAF & $=0.829$ & РИНЦ (Russia) & $=0.156$ & PIF (India) & $=1.940$ \\
\hline & GIF (Australia) & $=0.564$ & ESJI (KZ) & $=5.015$ & IBI (India) & $=4.260$ \\
\hline & JIF & $=1500$ & & & & \\
\hline
\end{tabular}

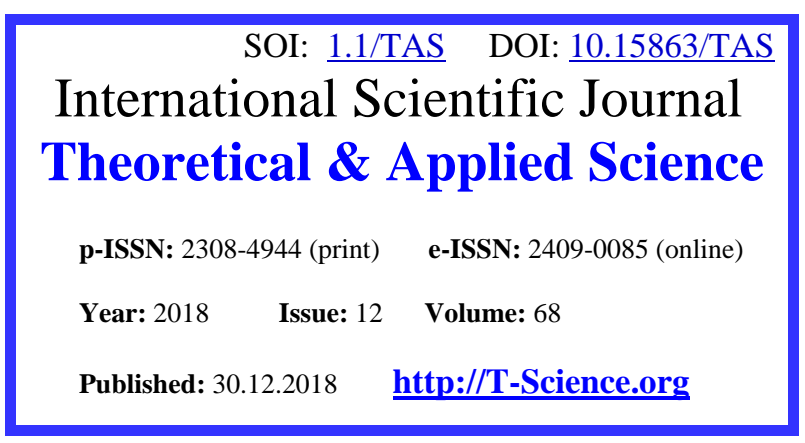

Section 31. economic research, finance, innovation, risk management
QR - Issue
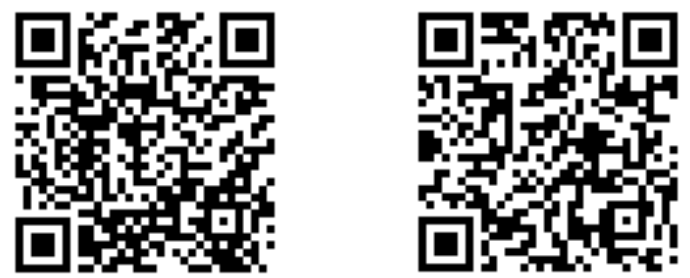

O.S. Kazakov

Candidate of Economic Sciences, Associate Professor Namangan Institute of Engineering and Technology, Namangan city, Republic of Uzbekistan kazakov.olimjon@inbox.ru

\title{
IMPROVING THE MANAGEMENT ACTIVITY OF THE FRUIT AND VEGETABLE INDUSTRY ENTERPRISES
}

Abstract: This article highlights the issues of effective management of fruit and vegetable industry enterprises. The creation of agro clusters in all sectors and sectors will make a great contribution to the development of the economy and increase the productivity of agricultural enterprises along with the production of competitive products. At the end of the article, recommendations for improving the management of the fruit and vegetable industry enterprises are proposed.

Key words: fruit and vegetable network, clusters, competitiveness, institutional structure, management process, functional processes.

Language: English

Citation: Kazakov, O. S. (2018). Improving the management activity of the fruit and vegetable industry enterprises. ISJ Theoretical \& Applied Science, 12 (68), 336-340.

Soi: http://s-o-i.org/1.1/TAS-12-68-50 Doi: crossef https://dx.doi.org/10.15863/TAS.2018.12.68.50

\section{Introduction}

At the current level of economic development, the country's agricultural sector is rapidly developing, as is the case with all industries and sectors. At the same time, the consistent implementation of large-scale reforms in the sphere, the current state of agriculture and all-round support of the state are yielding its results. Continuing structural reforms in all sectors of the country, unshakable continuation of structural reforms in the economy, primarily in agriculture, accelerated development of private property, entrepreneurship and small business, protection of macroeconomic balance, is a key priority. [1]

A number of activities are underway in the direction of agriculture development. Due to the large-scale implementation of the agrarian reforms in Uzbekistan, the economic freedoms of agricultural producers were expanded, the structure of large agricultural enterprises with low profitability and unprofitable enterprises was created, on the basis of which farms were established, material- technical base has been developed. Organizational and economic principles of sustainable economic activity through deepening of processing of agricultural raw materials, modernization, technical and technological re-equipment of agricultural production, optimization of farmland area parcels, creation of modern service infrastructure to support their activity was created. At the same time, special attention is paid to the deep processing of agricultural produce and the development of their storage infrastructure. As a result of carried out work, annual prices allow for seasonal increase of prices, uninterrupted supply of population with main types of agricultural products, expansion of export of these products, maintenance of price stability.

Materials and methods

In order to increase the efficiency of the fruitand-vegetable sector and to ensure consistent agricultural extension of the population throughout the year, the issues of agro-clusters formation have been studied. In order to carry out this research, a collection of materials on agriculture and its fruits and vegetables was utilized. Studies of foreign scientists in this direction have been investigated. In the study, the method of abstract thinking, the khash method, the specific analysis was used.

The Role of Fruit and Vegetable Sector in Agriculture and the Issues of the Creation of Agroclusters

In the agricultural structure, the fruit and vegetable sector has an important role and importance, which carries out tasks related to the 


\begin{tabular}{|c|c|c|c|c|c|c|}
\hline \multirow{4}{*}{ Impact Factor: } & ISRA (India) & $=3.117$ & SIS (USA) & $=0.912$ & ICV (Poland) & $=6.630$ \\
\hline & ISI (Dubai, UAE & $=0.829$ & РИНЦ (Russia) & $=0.156$ & PIF (India) & $=1.940$ \\
\hline & GIF (Australia) & $=0.564$ & ESJI (KZ) & $=\mathbf{5 . 0 1 5}$ & IBI (India) & $=4.260$ \\
\hline & JIF & $=1.500$ & SJIF (Morocco) & $=5.667$ & & \\
\hline
\end{tabular}

annual supply and export of fruit and vegetable products to the population. The accelerated and sustainable development of the fruits and vegetables sector is directly related to its competitiveness and modernization. Modernization, in turn, will create a promising competitive model of the fruit and vegetable complex, the strengthening of interaction between various managing subjects involved in the production, processing and sale of fruit and vegetable products, their optimal social structure and the organizational structure of agricultural producers the development of species. Formation of efficient agroclusters currently in the fruit and vegetable sector of the country is an important factor. Agro-clusters, which are set up in the fruit and vegetable sector of agriculture, are a new institutional structure. One of the pressing issues of modernity is the creation of not only the need to organize them, but also to organize them effectively. In many countries, theoretical and methodological aspects of agroclipurs have been studied. At the same time, it is necessary to study the theoretical and methodological aspects of effective agro-clusters in the fruit and vegetable industry of our country, taking into consideration that each country and the various stages of development of the economy have such specific features as the creation of such new structures. In the conditions of deepening of current market relations, effective organization of agro-clusters in the fruit and vegetable industry and organization of their activity on the basis of modern management principles are very important. [2]

First of all, it is necessary to analyze the theoretical nature of the concept of cluster. We know that the term cluster (when translated from the English word "cluster") is understood as an independent unit that combines several elements with one another, accumulating, group meaning and, to some extent, specific characteristics. The term "cluster" was used primarily in mathematics and natural sciences until it came to governance. In the 1970 's, economists from Sweden, K. Fredriksson and L. The Lindsmark used this term to determine the concentration of enterprises in a restricted area. In the 80 's of the 20th century, the scientific process Cluster terms porter is included as an economic category. In his opinion, the cluster is a geographical cross-sectoral association of companies and institutions operating in a particular area. The essence of agroclipster A.A. Nastin is well-founded: A geographically located, interconnected, and complementary, diverse ownership - family farms, farmers, and farmers, in order to combine agrococrats simultaneously and collaborate in production tasks and environmental protection. cooperatives, social and scientific organizations, educational institutions and advisory services. In scientific literature, we can find many more agrocluster rates. By analyzing, summarizing and summarizing them, we can now summarize the agroclusters in the agricultural and agro-market, as follows:

\section{- Agro-clusters in agriculture}

- preparation of agricultural land for agricultural production and the production of agricultural products, and reorganize the process of recycling, unilaterally integrate the storage and sales processes into a single chain and deliver high-tech innovations. Along with the classification, it consists of subjects of the economy engaged in raising the competitiveness of agricultural products both in domestic and foreign markets. In our opinion, the tariff given to the clusters in the fruit and vegetable industry will help explain the essence and functions of the fruits and vegetables. In the field of fruit and vegetable growing, agrocrocessors start with the process of land preparation for fruit and vegetable production, which means the delivery of the crop to consumers in a manner that does not violate their quality and effectiveness and benefit from it. The whole complex process is brought to life. At the present time, the importance of organizing and improving agro-clusters in the field of fruit and vegetable production, with the systemic governance activities becoming more and more evolving. [3]

\section{Increasing the efficiency of agro-clusters in the fruit and vegetable sector}

Building an agro-cluster in the fruit and vegetable sector is a key aspect of the issue, with the creation of an efficient agro-cluster based on the proper organization of its activities. It is important not only to organize agro-clusters, but also to build effective productivity. Achieving sustainable growth in the performance indicators determined by the ratio of access to agro-cluster results, and the increased efficiency of agro-clusters in ensuring their viability. There are a number of challenges to be pursued to ensure the effective functioning of agro-clusters in the fruit and vegetable sector, which includes:

a) All activities should be focused on raising the competitiveness of fruit and vegetable products and enhancing the economic potential of the regions. To do this, try to work at all stages in accordance with the regulations. In any case, it is impossible to get rid of the regulation.

b) to take measures to produce and increase the range of fruit and vegetable products in the regions;

c) developing a system of specific measures for their export, in addition to increasing the competitiveness of fruit and vegetable products;

d) Provide farmers who produce fruit and vegetable produce with a variety of fertile, disease resistant, and human health benefits. To carry out large-scale work in the research institutions operating for this purpose and to create varieties that meet the above requirements; 


\begin{tabular}{|c|c|c|c|c|c|c|}
\hline \multirow{4}{*}{ Impact Factor: } & ISRA (India) & $=3.117$ & SIS (USA) & $=0.912$ & ICV (Poland) & $=6.630$ \\
\hline & ISI (Dubai, UAI & $=0.829$ & РИНЦ (Russia) & $=0.156$ & PIF (India) & $=1.940$ \\
\hline & GIF (Australia) & $=0.564$ & ESJI (KZ) & $=5.015$ & IBI (India) & $=4.260$ \\
\hline & JIF & $=1.500$ & SJIF (Morocco) & $=5.667$ & & \\
\hline
\end{tabular}

d) further expand the network of infrastructure facilities serving the agro-cluster organizations in the fruit and vegetable sector;

d) introduce a system of preferential loans to meet the different needs of agro-clusters in the fruit and vegetable sector;

e) Establishment of trade houses for sale and sale of fruit and vegetable agro-bracing products in foreign countries.

i) relationships with experts, academics, and researchers should be taken into account in organizing the agro-cluster organizational structure in the fruit and vegetable sector. The most effective organizational structure should be accepted. [4]

In the agro-bazaar created in the fruit and vegetable sector, it is necessary to take into account and analyze the internal and external factors affecting their activities. It is important to distinguish between clear variables that affect agrocliparts and accept alternate variants. At agroclusteres, it is necessary to focus on the objectives of the ride. Activities should be undertaken to ensure that their strategic and tactical goals are achieved and that they achieve significant benefits as a result of their achievement. Given the dynamic change in the objectives, managers need to increase the responsibility for their achievement. In the organization of the agrocluster activity, it is necessary to pay more attention to the goal-action plan, which is the main scheme of management. [5] Once the goal is set, strategic and tactical action is taken to achieve that goal. Regular control over the expected outcome of the action is crucial. Before the goals have been set and action is taken to achieve them, it is necessary to create agrocluster organizational structures. Organizational structure of management in agroclusteres is achieved through the creation of divisions and subdivisions, which can contribute to the achievement of the goals. The importance of predicting how each unit in the organizational structure of agro cluster management will contribute to achieving the overall objective is extremely important.

It is important to designate each position and assignment in the organizational structure of the agro-clusters in the fruit and vegetable sector on a common ground. The purpose of the overall system should be primary and then the purpose of each unit. In determining the purpose of each unit, it is important to focus on coordination between the parts of the general system. It is important to note that the purpose of any division is not intended to be a common goal. For example, the increase in the amount of fruit and vegetable production should not have a negative impact on the quality and composition of products. First of all, the level of satisfaction of consumers' needs and the consumer value of fruit and vegetable products grown.

The correct selection of technology for the final crop production in agro-clusters in the fruit and vegetable industry is of great importance. Product acquisition technology, with low cost and high productivity, results in the output of agro-clusters in the network to exceed the cost of inputs. Trying to keep up this difference will increase your awareness and ensure efficiency.

Another important aspect of raising productivity of agroclusteras is the rational organization of labor activities. This is primarily due to the fact that staff selection and continuous professional development are the result of increased agro-clusters in the fruit and vegetable sector. Each employee should be consistent with the functions he / she performs, have a deep knowledge of the functional requirements, and continuously improve his / her professional skills. At the same time, it is important to organize their labor, control and analysis and to organize a system of incentives based on results. Every staff member in the fruit and vegetable sector is regularly monitored and evaluated. The rating of each employee in the network is determined. Based on this rating, they are encouraged or punished, that is, raising the burrows and taking measures such as decreasing or dismissing. Such activities will result in increased productivity and productivity of the workers in the agro-bazaar network. [6]

Organization of communication processes is also of great importance in raising the efficiency of agro-clusters in the fruit and vegetable sector. There is a need for effective communication between the network and the transfer of any information that is being transmitted only to the effectiveness of the communication. In order to eliminate the semantic and empathic factors that have a negative impact on the information exchange process, there is an ongoing effort. Information Achieving free movement between all agro-cluster divisions and gaining access to non-essential information increases the efficiency of the communication process. The effectiveness of the communication process will increase the effectiveness of decision-making in agro-bazaar. This will be an important factor in increasing the efficiency of agro-clusters in the fruit and vegetable sector.

\section{Implementing management activities in agroclusters \\ For the creation and operation of agro-clusters} effectively, it is necessary to use modern management models and to apply the management strategies that fit the current development level. In the fruit and vegetable growing industry, first of all, it is necessary to introduce the process of agroclusters based on the full process of management. [7]

The management process is a combination of interconnected, interrelated, and interconnected processes that are combined into a single target. This action is carried out in the overall objective of the 


\begin{tabular}{|c|c|c|c|c|c|c|}
\hline \multirow{4}{*}{ Impact Factor: } & ISRA (India) & $=3.117$ & SIS (USA) & $=0.912$ & ICV (Poland) & $=6.630$ \\
\hline & ISI (Dubai, UAI & $=0.829$ & РИНЦ (Russia) & $=0.156$ & PIF (India) & $=1.940$ \\
\hline & GIF (Australia) & $=0.564$ & ESJI (KZ) & $=5.015$ & IBI (India) & $=4.260$ \\
\hline & JIF & $=1.500$ & SJIF (Morocco) & $=5.667$ & & \\
\hline
\end{tabular}

organization and is supported by all elements. Management process is a set of actions that are carried out by managerial managers on the basis of professional, functional and qualitative division of labor. They make their own management tools as their primary tool, and perform their management functions in their work, following the principles of management. In the work of fruit and vegetable agroclusters, the complexity of the management process increases. Because here various types of activities are interconnected and management processes need to be carried out in a very rational way to make their work more effective. At the fruit and vegetable agrofactories, there are enterprises and organizations involved in agriculture, industry, transport, construction and service industries. Because of the inherent features of management in these areas, management of them in a single center creates some problems.

Effective activity creates the need for effective management technology in agro-bazaars in the fruit and vegetable sector. In order to introduce management technology in agroclusteres, it is necessary to analyze and analyze tasks, actions and operations, which are part of the management technology, and their parts, methods and activities. In order to carry out such managerial actions, it is necessary to introduce a more detailed study of the division of labor into agrocroclover management. This division of labor leads to the increase in management efficiency and productivity. [8]

Improvement of professional division of labor in the management of the fruit and vegetable industry envisages the separation of tasks among professionals by types of activities. For example, an economist, accountant, an economist, an accountant, and so on. In order for the management technology to be effective, the division of skilled labor should also be revised and further deepened. It is desirable to organize division heads in departments of industrial production of agroclotheses (canning, juice production, grain processing, etc.), ie division managers in several categories. [9] All of them are provided with service duties. Managers who carry out their assigned task assignments will work for the benefit of agro-cluster activities and contribute to the achievement of the goals. The agrocluster's total goal is to equal 1, and for each category, the coefficient of coefficients is given to managers. As a result, this coefficient is monitored on a regular basis and, if necessary, using motivational channels. [10]

In agrocluster, complex functional processes that are not yet up to date. At the same time, various sectors such as agricultural production, industrial production and long-term storage of finished products are kept without disturbance of quality and consumption value. [11] It is necessary to properly organize the functional processes in the management system so that they can work together effectively. It is necessary to determine the amount, sequence and nature of the actions to be taken in management activity. As a result, optimal management technology is selected. Management of such complex systems is carried out with specific difficulties. For this reason, agro-clusters in the fruit and vegetable sector should regularly use systematic analysis.

In the fruit and vegetable sector, aggressive agro-clusters should be properly adjusted to establish effective productivity. It is important to note that this management policy is consistent with the strategic objectives of agro-clusters. A set of conditions must be met to establish a business management policy for businesses and businesses. first of all, the agroclimatic management policy must be in line with the actual situation and the current legislation. The second important prerequisite is that the management targets at different parts and levels of the agroclimatic complement each other and achieve the necessary motivation. The third requirement is that the agrocluster management policy should be accurate and clear to all participants.

\section{Conclusions}

In order to establish agro-clusters in the fruit and vegetable sector and to ensure their successful operation, it is necessary first of all to introduce modern management principles, methods and tools in these structures. Achieving the benefits of the system can be achieved by selecting, evaluating, and responding to important internal and external factors in the agro-clusters in the fruit and vegetable sector. In this regard, one should pay attention to the correct selection of agro-cluster technology and the efficiency of its employees. In the agro-bazaar created in the fruit and vegetable sector, the implementation of the above-mentioned management orientation is a major factor. Implementation of these targets and accomplishment of tasks will contribute to the effective agro-cluster production in the fruit and vegetable sector and will serve to meet the demand for products of the fruit and vegetable sector not only seasonally, but also throughout the year, to meet the highest quality and health of the population. At the same time, exports of fruit and vegetable products will increase. 


\begin{tabular}{llllll} 
& ISRA (India) $=\mathbf{3 . 1 1 7}$ & SIS (USA) $=\mathbf{0 . 9 1 2}$ & ICV (Poland) & $\mathbf{= 6 . 6 3 0}$ \\
Impact Factor: & ISI (Dubai, UAE) $=\mathbf{0 . 8 2 9}$ & PUHL (Russia) $=\mathbf{0 . 1 5 6}$ & PIF (India) & $=\mathbf{1 . 9 4 0}$ \\
& GIF (Australia) $=\mathbf{0 . 5 6 4}$ & ESJI (KZ) & $\mathbf{5 . 0 1 5}$ & IBI (India) & $=\mathbf{4 . 2 6 0}$ \\
& JIF & $\mathbf{1 . 5 0 0}$ & SJIF (Morocco) $=\mathbf{5 . 6 6 7}$ & & \\
\hline
\end{tabular}

\section{References:}

1. (2017, Feb. 11). The Decree of the President of the Republic of Uzbekistan "On the Strategy for the Further Development of the Republic of Uzbekistan" Tashkent, February 7, 2017 "Namangan haqiqati" newspaper, № 12 (19321).

2. Balashov, A. P. (2014). Organization theory and organizational behavior: studies. Allowance. (p.304). M .: University textbook: INFRA-M.

3. Vernigor, N. F. (2004). Sustainability of agricultural enterprises in modern conditions. Barnaul: Polygraphist LLC.

4. Yuldashev, N. K., \& Kazakov, O. S. (2017). Fundamentals of Economics and Management. Tashkent: Economics.

5. Kazakov, O. S., et al. (2016). The use of local raw materials in agriculture. Monograph. Namangan, Namangan.
6. Kazakov, O. S., \& Ahmedkhodjaev, X. T. (2017). Fundamentals of management. Tashkent: Ilm-Ziyo.

7. Kazakov, O. (2016). Actual issues of agricultural production. Namangan, NamMTI.

8. Samatov, G. A., et al. (2012). Agricultural Economics and Management. Textbook. T: Chulpon.

9. (2011). Problems of development of a market economy. A collective monograph, ed. member-correspondent RAS V.A. Tsvetkova (Eds.). (p. 97-113). M .: CEMI RAS.

10. Repin, V. V., \& Elifer, V. G. (2004). Process approach to management. Business process modeling. (p.544). M .: RIA "Standards and Quality".

11. Romanov, A. E., \& Arashukov, V. P. (2008). Agribusiness clusters of Russia - a myth or a perspective? Economics of S.-H. and pererabat. Enterprises, №7, 27-29. 